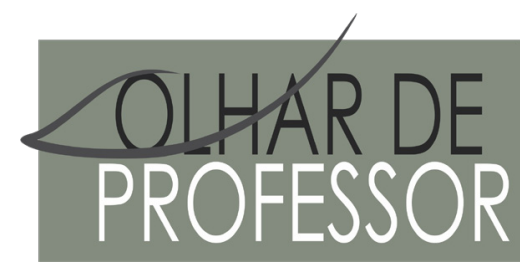

DOI: 10.5212/OLHARPROFR.v23.2020.16918.209209230240.0924

\title{
ENTREVISTA COM SANDRA ZÁKIA: REFLEXÕES SOBRE AS AVALIAÇÕES EM LARGA ESCALA E SEUS EFEITOS NO CONTEXTO EDUCACIONAL
}

\author{
CLICIA BUHRER MARTINS* \\ ELISMARA ZAIAS KAILER ${ }^{* *}$
}

Sandra Maria Zákia Lian Sousa é professora aposentada da Universidade de São Paulo, e atua no programa de Pós-Graduação em Educação desta instituição. Desenvolve estudos na área da Educação, com ênfase em Política, Planejamento e Avaliação Educacional. Sandra Zákia, como é mais conhecida no meio acadêmico, é autora de inúmeros textos publicados em periódicos da área da avaliação educacional e também de capítulos de livros sobre os diversos domínios da avaliação. Dentre alguns temas desenvolvidos pela autora destacam-se: a gestão de escolas municipais no Brasil; relações entre avaliação e gestão educacional em municípios e estados brasileiros; avaliação de programas educacionais incentivados pelo governo federal; políticas de avaliação dos sistemas educacionais, entre outros. As pesquisas realizadas pela autora permitem que os estudiosos em avaliação sistematizem reflexões mais apuradas a respeito deste campo, e, considerando a temática do presente dossiê, sobre a avaliação em larga escala a partir das análises em nível macro e micro que estabelece em suas produções.

O convite à professora Sandra Zákia para conceder a presente entrevista às coordenadoras editoriais do Dossiê “Avaliação em larga escala no contexto da Educação Básica” da Revista Olhar de Professor foi feito via email, assim como a realização da entrevista em si, que se deu entre os dias 31 de março e 28 de abril de 2020.

Entrevistadoras (E): Você considera que os sistemas de avaliação em larga escala nacional, estadual e municipal contribuem para a melhoria da qualidade do processo de ensino-aprendizagem nas escolas? Se sim, de que forma? Se não, por quê?

Sandra Zákia: Os processos avaliativos sempre cumprem papel indutor. No caso das avaliações em larga escala, que se caracterizam, em geral, por aplicação de testes aos estudantes, as pesquisas têm mostrado que seus efeitos nas escolas de educação básica são diversos, pois há especificidades nos delineamentos adotados, mas, principalmente, são diversos os usos que vêm sendo feitos de seus resultados. Assim, alguns realçam suas contribuições para a melhoria do processo de ensino e outros apontam desserviços para a organização do trabalho escolar e o processo de ensino.

O modo como as escolas vêm lidando com essas avaliações depende, em grande parte, dos gestores da rede ou sistema de ensino, os seja, como seus resultados são levados em conta para a implementação de ações junto às escolas e seus professores. Ao que parece, um aspecto inicial a ser considerado é como as escolas vêm tendo acesso aos resultados das avaliações. O acesso aos

\footnotetext{
* Licenciada em Pedagogia pela Universidade Estadual de Ponta Grossa (UEPG), Mestre em Educação pela Universidade Estadual de Ponta Grossa (UEPG), Doutora em Educação pela Pontifícia Universidade Católica de São Paulo (PUC/SP). Professora da UEPG no Departamento de Pedagogia da UEPG. Integrante do Grupo de Pesquisas em Política Educacional e Avaliação (GEPPEA) da UEPG. Membro da Rede Universitas/Br. E-mail: cliciabuhrermartins@gmail.com

${ }^{* *}$ Licenciada em Pedagogia pela Universidade Estadual de Ponta Grossa (UEPG), Mestre em Educação pela mesma instituição e Doutora em Educação pela Universidade de São Paulo (USP). É professora adjunta do Departamento de Pedagogia da UEPG e integrante do Grupo de Estudos e Pesquisas em Política Educacional e Avaliação (GEPPEA). (http://www3.uepg.br/geppea/). Membro da Rede Universitas/Br. E-mail: zaias.elismara@gmail.com
} 
resultados usualmente se dá por meio de divulgação feita pela secretaria de educação. Também, as secretarias que investem na divulgação dos resultados das avaliações externas para as escolas tendem a acoplar à divulgação uma análise que, em geral, se volta a apontar os pontos e fracos de desempenho dos alunos, tendo como referência a matriz de avaliação.

Difundir os resultados das avaliações é um passo importante para potencializar seu uso pelas escolas. No entanto, o modo como se dá essa divulgação e interpretação nem sempre é capaz de potencializar ações das escolas que sejam eficazes para promover o aprimoramento do processo de ensino. Pouco a pouco esse procedimento tem levado os profissionais das escolas a restringirem a análise da qualidade do ensino e da aprendizagem dos estudantes aos resultados das avaliações, sem levar em conta que as provas representam um pequeno recorte do currículo. É comum os estudos revelarem que as escolas buscam pautar o ensino nessas avaliações, valorizando as disciplinas que são testadas em detrimento das demais, sendo frequente a aplicação de simulados como atividade preparatória para os testes. Ensinar para o teste é uma resposta equivocada, que revela desconsideração da amplitude do processo educacional e do currículo escolar e da complexidade do processo de aprendizagem.

A interpretação dos desempenhos dos estudantes nas avaliações em larga escala pode se constituir em um dos elementos que informa decisões que visem a melhoria do trabalho escolar, desde que interpretados à luz do projeto pedagógico da escola e em articulação com as condições intra e extraescolares. Um trabalho dessa natureza supõe lidar com os resultados das avaliações em larga escala como um dos indicadores a ser considerado na avaliação do trabalho escolar.

Avaliar apenas resultados sem articulação com uma avaliação de insumos e processos de trabalho e, além disso, restringir a noção de resultados do trabalho escolar a desempenhos apresentados pelos estudantes em algumas disciplinas não contribui, em meu entender, para a melhoria do ensino e da aprendizagem. Esse é um desafio que precisa ser enfrentado.

E: Na sua opinião, quais as possibilidades das escolas trabalharem com os resultados das avaliações em larga escala e reconhecerem a sua importância na prática institucional?

Sandra Zákia: Com a implantação, pelo governo federal, do Sistema de Avaliação da Educação Básica, nos anos noventa, as escolas vêm assimilando a ideia de uma avaliação de seus estudantes realizada por agentes externos à escola, o que se intensificou com a organização de propostas próprias por estados e municípios. Embora já convivam com essas avaliações há quase 30 anos, penso que ainda há dificuldades para que as escolas lidem com os resultados das avaliações externas de modo a que ganhem significado no contexto institucional, ou seja, que seus resultados venham a ser analisados pelos integrantes da escola, em articulação com suas propostas e práticas, de modo a iluminar possibilidades de ação voltadas para a melhoria do ensino e a garantia da aprendizagem dos estudantes.

É fato que as iniciativas de avaliação foram instituídas, em sua origem, para apoiar a formulação e implementação de políticas educacionais, em nível macro, no entanto, paulatinamente, agregam aos seus propósitos difundir informações que subsidiem as escolas em suas decisões e ações.

A questão trazida por vocês indaga sobre possibilidades das escolas trabalharem com os resultados de avaliações em larga escala e reconhecerem a sua importância na prática institucional. Penso que as possibilidades existem e os caminhos a serem percorridos serão específicos de cada escola, tendo em conta seu contexto e o projeto pedagógico.

É recorrente, nas propostas de avaliação, o anúncio de que sua principal finalidade é contribuir para a melhoria do ensino, promovendo a aprendizagem de todos os estudantes. Não basta os profissionais da escola conhecerem esta finalidade, é preciso acreditar que a avaliação será conduzida com esse propósito.

Nesse sentido, um dos aspectos que merece ser considerado é que usualmente os profissionais das escolas não se sentem envolvidos com esses processos e, pior, se sentem ameaçados, dado que os resultados apresentados pelos estudantes são muitas vezes, erroneamente, associados quase 
que exclusivamente ao desempenho docente. Essa percepção foi acentuada com a criação, em várias redes de ensino, de programas de incentivos, monetários ou não, que associam prêmios e punições aos resultados obtidos pelos estudantes nos testes. A difusão dos resultados por meio de ranqueamentos, os quais apoiam programas de mérito, são encaminhamentos que tendem a gerar uma atitude de resistência nas instituições que não obtêm boas classificações, pois escolas e seus profissionais se sentem culpabilizados. Além disso, não podemos esquecer que a segmentação de professores e escolas tem como consequência a intensificação das desigualdades educacionais e sociais o que também explica resistências manifestas por profissionais que lutam pela democratização da educação.

Portanto, alinhar os propósitos anunciados, o modo de conduzir as avaliações e o uso de seus resultados é um passo inicial para que ganhem sentido na prática institucional. Esse é o alicerce para que ações de formação dos profissionais tenham potencial de induzir as equipes escolares a utilizarem as informações por elas produzidas para analisar e, eventualmente, rever práticas pedagógicas e didáticas.

E: Como você percebe a relação entre as avaliações em larga escala e os processos de autoavaliação institucional nas escolas?

Sandra Zákia: Falar de autoavaliação institucional nas escolas remete a práticas em que os seus diversos integrantes realizem, coletivamente, um julgamento das propostas e ações desenvolvidas e de seus resultados e efeitos, com vistas ao replanejamento do trabalho. A autoavaliação precisa se apoiar em informações diversas, de diferentes fontes, produzidas tanto por agentes internos da escola, quanto agentes externos, portanto, resultados de avaliações em larga escala podem se constituir em uma das referências no processo de autoavaliação.

Seria desejável que professores, gestores, funcionários, estudantes e seus familiares produzissem uma análise do trabalho com base em informações diversas, não só aquelas por eles produzidas. Nessa perspectiva deveriam recorrer, no processo de autoavaliação, a informações produzidas por profissionais da rede que atuam em outras instâncias, como os supervisores e, até mesmo, buscar conhecer como segmentos e representantes da comunidade onde se situa a escola avaliam o seu trabalho. Com essa perspectiva é que são úteis, para compor a base de informações para a autoavaliação institucional, a consulta a bancos de dados com informações e estatísticas disponibilizados por órgãos públicos e a análise dos resultados das avaliações em larga escala, conduzidas por agentes externos à escola.

Um olhar que articule avaliações internas e externas tem potencial para contribuir com o aprimoramento do ensino e da aprendizagem dos alunos. Identificar recorrências e discrepâncias, interpretar tendências dos resultados, envolvendo o coletivo da escola, é um caminho promissor. Inclusive, contribui para que os resultados das avaliações externas não sejam equivocadamente interpretados como de interesse apenas dos professores responsáveis pelos estudantes e/ou disciplinas avaliadas.

Vale lembrar, no entanto, que a avaliação institucional focaliza a análise, de modo sistemático, da escola como um todo e não apenas o desempenho dos estudantes, tendo como referência o seu projeto pedagógico. Assim, abrange aspectos diversos que vão desde a apreciação da atuação dos profissionais da escola, das propostas pedagógicas, das condições e relações de trabalho; dos equipamentos e materiais disponíveis; entre outras dimensões.

Embora vocês tenham focalizado a questão na autoavaliação institucional das escolas, quero lembrar que esta é uma atividade que deveria ser posta como vertente dos processos avaliativos da atuação de todas as instâncias de uma rede de ensino, ou seja, os órgãos centrais e regionais, e não apenas as escolas, podem se beneficiar da autoavaliação institucional para analisar e balizar sua atuação. 
E: Qual a relação que você estabelece entre os resultados das avaliações em larga escala e a avaliação da aprendizagem dos alunos nas escolas?

Sandra Zákia: Podemos colocar essa indagação de outro modo, problematizando ser possível ou não que a escola estabeleça um diálogo entre avaliação em larga escala e avaliação da aprendizagem, tendo em conta que são atividades cumprem finalidades distintas e possuem características próprias.

A avaliação da aprendizagem, compreendida como a avaliação que é realizada no âmbito da escola, tendo como principal responsável por sua condução o professor, se constitui em um processo inerente à ação educacional, que ocorre de modo contínuo e tem como função nuclear diagnosticar e favorecer o desenvolvimento dos alunos, sendo que seus resultados devem apoiar e orientar processos de planejamento e de mudança. No cotidiano do trabalho escolar ganha destaque a função formativa da avaliação, que apoia a implementação de intervenções que visam promover a aprendizagem de todos os estudantes. A avaliação formativa possibilita aos estudantes compreenderem como estão caminhando no percurso escolar, seus avanços e dificuldades, de modo a que lhes sejam oportunizadas condições para que alcance um bom desempenho escolar.

Ou seja, as informações oriundas dos processos de avaliação da aprendizagem se constituem em subsídios para o planejamento e replanejamento do trabalho escolar, permitem intervenções contínuas, ao longo do processo de trabalho. Tanto o delineamento de como será conduzida a avaliação como as decisões tomadas com base em seus resultados são ações circunscritas a escola, tendo como parâmetro o seu projeto pedagógico.

As avaliações em larga escala são concebidas e conduzidas por órgãos externos à escola, usualmente recorrem a aplicação de testes padronizados para obter evidências da aprendizagem dos estudantes ao final de um ou mais anos da trajetória de escolarização, abrangendo redes de ensino. Coleta informações pontuais, em algum momento dessa trajetória, portanto, não tem caráter processual. Pela sua natureza, são avaliações que usualmente focam resultados. Os desempenhos apresentados pelos estudantes são apreciados com base em escalas de proficiência que estabelecem aprendizagens esperadas ao final de um dado ano escolar, em algumas disciplinas. A depender da metodologia utilizada, apoiam comparações dos resultados obtidos pelos estudantes no decorrer do tempo e também entre grupos.

Diferentemente das avaliações de aprendizagem que se realizam sob responsabilidade da escola, não se propõem a abranger um julgamento abrangente dos objetivos educacionais; busca identificar a proficiência dos estudantes em determinadas disciplinas escolares.

Como já disse, no Brasil, as primeiras iniciativas de avaliação tinham como alvo subsidiar a formulação e reformulação de políticas educacionais, no entanto, gradualmente incorporaram a perspectiva de que seus resultados fossem, também, apropriados pelas escolas. Passaram a ser aplicadas avaliações censitárias e não apenas amostrais.

Vejam, o que quero demarcar é que avaliações em larga escala e avaliações de aprendizagem têm finalidades, propósitos, abrangência e procedimentos específicos, portanto, cumprem papéis distintos.

A escola pode se beneficiar dos resultados das avaliações externas, como já mencionei ao comentar sobre avaliação institucional, os quais expressam como se situa em relação a expectativas e parâmetros de qualidade definidos por órgãos governamentais, seja de âmbito federal, estadual ou municipal. No entanto, seus resultados não podem ser tomados como expressão de qualidade da escola, porque não o são. São um dos elementos de referência para avaliação do trabalho escolar. É fundamental que a avaliação da aprendizagem e a avaliação em larga escala sejam tratadas em suas especificidades, só assim podem contribuir para a melhoria da educação.

E: Para você, quais as relações que se estabelecem entre as atuais políticas de currículo e as políticas de avaliação em larga escala?

Sandra Zákia: Currículo e avaliação são facetas interdependentes, o que se estabelece em termos de currículo tende a condicionar o que se avalia e, reciprocamente, o que se avalia orienta o currículo. Trato dessa temática em texto escrito para o ENDIPE-2020, no qual apresento considerações 
sobre avaliação e currículo da escola básica, com foco em iniciativas do governo federal, implementadas no Brasil, que tendem a se materializar, de modo mais articulado, com a aprovação da Base Nacional Comum Curricular. No caso do ensino fundamental a Base define competências e habilidades, bem como conteúdos, chamados “objetos de conhecimento”. Conforme a Constituição Federal é prerrogativa da União definir conteúdos mínimos, assim como a avaliação dos sistemas, a questão a ser discutida é como a União vem implementando esta prerrogativa legal.

Considerando os rumos adotados nas avaliações em larga escala e nas prescrições curriculares o que se evidencia é o recrudescimento e consolidação da lógica de gestão educacional orientada pelo controle de resultados. Falo em recrudescimento, pois temos que levar em conta que anteriormente à aprovação da BNCC já circulavam parâmetros e orientações curriculares no âmbito das redes de ensino, que aliadas a implantação das avaliações externas e em larga escala, já vinham se constituindo como fortes indutores de currículos unificados.

A pressão exercida pela avaliação externa sobre a escola, induzindo à padronização do que os estudantes devem aprender, se mantém, assim como os traços da gestão por resultados, que incita a competição e a meritocracia, mas, atualmente, ancorados em um contexto ultraconservador de ataque ao caráter público da educação.

O governo Bolsonaro difunde e defende uma concepção de educação e de mundo ultraconservadora e antidemocrática, que reflete uma ideologia de extrema direita, que, dentre as tantas ofensivas para a educação pública, busca controlar a seleção do "conteúdo" a ser legitimado pelas avaliações. Vale lembrar a interferência na Prova do ENEM, chegando a constituir uma comissão para realizar leitura e seleção dos itens que iriam integrar a prova em 2019. Também, vale lembrar manifestação do presidente que revelou intenção de interferir na seleção de livros didáticos a serem disponibilizados às escolas, o que incide nos currículos e nas avaliações, dado que são os livros didáticos os principais veículos que traduzem o currículo oficial.

Mas, ainda bem, que o currículo vivido nas escolas não é mera expressão do que está prescrito, o que significa que as escolas têm espaço para a vivência de projetos comprometidos com a garantia do direito a educação pública, de qualidade para todos, o que supõe ampliação da própria noção de avaliação, indo além da verificação de desempenhos de alunos em provas, abarcando uma análise das condições em que esses desempenhos são produzidos.

E: Muitas vezes, as redes de ensino têm estruturado o trabalho pedagógico nas escolas a partir da nota obtida no IDEB. Assim, as redes planejam metas a serem atingidas com o objetivo de aumentar este índice. Como você percebe esta realidade?

Sandra Zákia: Essa é uma constatação reiterada por diversas pesquisas. A dissertação de Ligia Sanches, que analisou aproximadamente 400 trabalhos de mestrado e doutorado que tratam do Ideb, desenvolvidos entre os anos de 2007 e 2015, traz indicações que indicam o acolhimento que este Índice alcançou no país, se constituindo em forte indutor de políticas e programas em estados e municípios brasileiros. Ainda, o Ideb levou a maior atenção aos resultados de desempenho de alunos nas avaliações em larga escala.

Assumido no âmbito da gestão educacional como um indicador que sintetiza a noção de qualidade da educação, cada vez mais é utilizado como referência para a gestão educacional e formulação de políticas, sendo que diversos estados e municípios criaram seus próprios índices de qualidade inspirados no Ideb, o que reforça a interpretação de sua força na gestão educacional, como parâmetro de julgamento da qualidade da educação, mesmo que contemple algumas facetas dessa qualidade - aprendizagem e fluxo.

Entendo que o problema central a ser discutido não é o fato das redes planejarem metas a serem atingidas, que contemplem a intenção de aumentar este Índice, mas, sim, a natureza das ações que são desenvolvidas para alcance dessas metas. Os projetos e ações precisam passar pelo crivo de seu potencial de promover o desenvolvimento profissional dos docentes e a permanência na escola, com sucesso, de todos os estudantes. 
Nesse sentido, é fundamental que os profissionais das redes se apropriem das contribuições e limites das avaliações em larga escala, o que não é favorecido quando avaliações são conduzidas por agentes contratados, externos às redes. A não participação de agentes internos, implica em não domínio, pelos profissionais da rede, dessas avaliações, seja dos requisitos exigidos para sua formulação, seja dos exigidos para interpretação de seus resultados.

Digo isso, pois muitas vezes, avaliações externas e em larga escala, estaduais e municipais, acompanhadas de criação de índices de qualidade, têm sido concebidas e desenvolvidas por agentes externos às redes, terceirizando-se para empresas, ONGs ou mesmo a consultores independentes a elaboração das testagens , a interpretação dos resultados e, até mesmo, a elaboração de relatórios que visam orientar professores em atividades didáticas ou gestores na condução de ações de formação continuada de profissionais da rede. Ainda, quando redes adotam sistemas privados de ensino é comum estes virem acompanhados de propostas de testagens de desempenho dos estudantes. Esse modo de conduzir as avaliações abalam a gestão pública da escola pública, significando não só a transferência de recursos públicos para terceirizados como também situa iniciativas de avaliação no âmbito do mercado.

E: Podemos considerar as políticas de avaliação em larga escala como instrumentos de gestão para os estados e municípios. Nesse contexto, as avaliações podem estar relacionadas à regulação, ao gerencialismo, ao accountability, às políticas de descentralização, entre outros. Como você compreende estes aspectos na efetivação das políticas de avaliação em larga escala?

Sandra Zákia: Nas respostas anteriores fiz indicações que situam as avaliações em larga escala como instrumento de gestão educacional e também mencionei o uso de seus resultados para responsabilização de escolas e professores. Talvez seja oportuno complementar o que foi dito, explorando a noção de accountabilty, que se insere na perspectiva de uma administração da educação voltada para resultados, com metas e indicadores estabelecidos, que passam a ser controlados e cobrados pelos gestores, sendo também induzido seu acompanhamento e cobrança pela sociedade.

A noção de accountability vem sendo tratada nas políticas educacionais tanto no sentido de prestação de contas à sociedade quanto no de responsabilização. Essas dimensões do conceito podem respaldar projetos democráticos de gestão pública.

No entanto, na prática, em geral essa noção vem associada a iniciativas de dar transparência e publicização aos resultados de avaliações em larga escala, por meio de rankings e restringindo-se a responsabilidade por eles, quase sempre, exclusivamente aos gestores que atuam nas escolas. A apreciação da atuação das diversas instâncias da rede, também responsáveis pela concretização de uma educação escolar de qualidade, ficam ausentes da produção de tal ou qual resultado. Ainda, associar aos resultados incentivos e sanções, sob uma lógica concorrencial, tende a gerar projetos excludentes. O uso de bonificações induz à redução curricular, sob a suposição de que focalizar conteúdos que caem nos testes leva a obtenção de melhores pontuações, além de induzirem iniciativas de segregação ou exclusão de estudantes que não apresentem bom desempenho nos testes.

Assumir a noção de accountability com base em discursos e ações que se pautam pela meritocracia conduz à naturalização das desigualdades educacionais, negando o que anunciam os discursos e programas governamentais que propalam a busca de equidade e qualidade educacional para todos.

\section{E: Até o presente momento, quais os principais avanços e retrocessos que você aponta em relação ao Sistema de Avaliação da Educação Básica no Brasil?}

Sandra Zákia: Recente avanço ocorreu com as mudanças no Saeb, a partir de 2019, ao se incluir creches e pré-escolas no Sistema de Avaliação da Educação Básica, pois, até então, a educação infantil não integrava o sistema. De acordo com o que prevê o Plano Nacional de Educação, essa avaliação foi realizada com vistas a analisar as condições de oferta da educação infantil, por meio de questionários aplicados, em caráter amostral, a gestores, diretores e professores de instituições públicas e conveniadas. No entanto, os resultados não foram divulgados e ainda não 
se tem clareza do uso que deles será feito, o que não nos permite analisar as reais contribuições dessa alteração no Saeb.

O que quero demarcar, e que já foi explorado em alguns textos de minha autoria, são alguns pontos que considero que podem representar avanços no delineamento de um sistema nacional de avaliação da educação básica. Afirmo que a avaliação é um caminho promissor para concretização do direito à educação, no entanto, não pode ser reduzida a medida de proficiência dos alunos, nem seus resultados serem interpretados exclusivamente como responsabilidade das escolas e dos alunos e suas famílias. Em um artigo que trato de concepções de qualidade da educação básica forjadas por meio de avaliações em larga escala, sintetizo alguns aspectos, que aqui reproduzo: avaliações devem possibilitar o julgamento da realidade educacional - em sua diversidade - e apoiar políticas e programas, desde os níveis centrais até a escola; produzir informações capazes de balizar iniciativas das diversas instâncias governamentais; ser abrangentes, abarcando indicadores relativos a acesso, insumos, processos e resultados; considerar os determinantes intra e extra institucionais que condicionam a qualidade da educação; induzir ao estabelecimento de relações compartilhadas, remetendo a que se dê centralidade ao controle social da qualidade da educação.

Tenho explorado, também, a noção de sistemática de avaliação, o que supõe assumir a avaliação como processo, que requer o delineamento de atividades inter-relacionadas que garantam um fluxo de produção de informações, análise, julgamento e decisões que apoiem a execução de ações desde os órgãos centrais até as escolas.

Por fim, reitero que é preciso superar a superposição de iniciativas de avaliação em larga escala, o que implica em colaboração e ações articuladas entre governo federal e governos estaduais e municipais.

Entrevistadoras: Agradecemos imensamente pela entrevista e pelas valiosas contribuições para os estudos, discussões e reflexões na área da avaliação educacional, principalmente da avaliação em larga escala. 